\title{
Self-fertility Evaluations of Northern-adapted Rabbiteye Blueberry Hybrids
}

\author{
Mark K. Ehlenfeldt ${ }^{1}$ \\ U.S. Department of Agriculture, Agricultural Research Service, P.E. \\ Marucci Center for Blueberry and Cranberry Research and Extension, \\ 125A Lake Oswego Road, Chatsworth, NJ 08019
}

\section{Matthew Kramer \\ USDA-ARS, Biometrical Consulting Service, Henry A. Wallace Agricultural Research Center, Beltsville, MD 20705}

Additional index words. highbush, $V$. constablaei, $V$. corymbosum, V. virgatum, $V$. ashei

\begin{abstract}
Rabbiteye blueberry hybrids that the U.S. Department of Agriculture, Agricultural Research Service (USDA-ARS) program has bred for northern adaptation are combinations of $6 x \mathrm{~V}$. ashei Reade, $6 x \mathrm{~V}$. constablaei Gray, $4 x \mathrm{~V}$. corymbosum L., and $2 x \mathrm{~V}$. darrowii Camp germplasm at the hexaploid level and are generally composed of $\mathbf{5 0 \%}$ or greater $\boldsymbol{V}$. ashei (rabbiteye) germplasm. Four northern-adapted rabbiteye (NRE) selections (US 1043, US 1045, US 1056, US 1057), four rabbiteye standards ('Brightwell', 'Climax', 'Tifblue', 'Woodard'), two rabbiteye $\times V$. constablaei derivatives ('Little Giant', 'Snowflake'), and two highbush standards ('Duke', 'Bluecrop') were pollinated under greenhouse conditions with either self-pollen or a multicultivar, bulk-pollen mixture (appropriate to ploidy level and species) to determine the relative requirements for cross-pollination among NRE selections. Fruit set, berry weight, and seed set were subsequently evaluated. The results suggest that NRE selections, in general, exhibit crosspollination needs intermediate to the parent types such that: rabbiteye $>$ northern rabbiteye $>$ highbush (i.e., rabbiteye has the lowest self-fertility and the greatest need for cross-pollination). Considerable variation existed among the NRE selections tested, which suggests that it might be possible to select clones with good levels of self-fertility, potentially equivalent to that of highbush blueberry.
\end{abstract}

Highbush blueberry (Vaccinium corymbosum L.) cultivars are considered, in general, to be adequately self-fertile/self-fruitful (Merrill, 1936); however, numerous studies have demonstrated the value of cross-pollination to fruit set, fruit size, development time, etc. (Coville, 1921; Ehlenfeldt, 2001; Meader and Darrow, 1947). In contrast, rabbiteye blueberry ( $V$. ashei Reade) cultivars are considered overwhelmingly self-incompatible (Brightwell et al., 1955; El-Agamy et al., 1981) and critically dependent on crosspollination (Meader and Darrow, 1944), although some indications of self-fertility in rabbiteye have been noted (Krewer and NeSmith, 2006).

In breeding for improved cold-hardiness in rabbiteye blueberry types, we have selected clones that we have termed NRE (Ehlenfeldt et al., 2007, 2012). These selections are a composite of several species: $6 x$ $V$. ashei (rabbiteye), a vigorous hexaploid species native to the southeastern United States as well as Texas; $6 x \mathrm{~V}$. constablaei, a self-fertile, highbush-like, high-altitude

Received for publication 12 Sept. 2012. Accepted for publication 15 Oct. 2012.

${ }^{1}$ To whom reprint requests should be addressed; e-mail mark.ehlenfeldt@ars.usda.gov. species found in northern Georgia, western North Carolina, and eastern Tennessee; $2 x$ $V$. darrowii, a low-chill species native to Florida and adjacent states that has been used in the development of southern highbush; and $4 x V$. corymbosum, the northernadapted species considered to be typical highbush blueberry, native to a wide range of temperate areas in the eastern third of North America. Considerable vigor is imparted to NRE selections by the $V$. ashei component, and these selections are envisioned as possible late-season alternatives to highbush cultivars. Rabbiteye blueberry acreage has remained relatively stagnant in acreage in the southern United States, whereas the acreage of earlier ripening southern highbush cultivars has increased (Strik and Yarborough, 2005). At the same time, growers in some more northern areas such as New Jersey and Oregon are experimenting with some of the more robust traditional rabbiteye cultivars (i.e., not northern-adapted) as a way to extend the fruiting season (Ehlenfeldt, personal observation). One critical piece of information to know about NRE selections is how they compare with highbush and rabbiteye with respect to self-fertility and their relative need for cross-pollination.

Twelve selections of varied composition were chosen for this study: four NRE selections, four rabbiteye (RE) cultivar standards, two rabbiteye $\times V$. constablaei (RE-CON) hybrids, and two highbush standards (HB). These selections were compared, when either self- or cross-pollinated, for fruit set, berry weight, and seed development.

\section{Materials and Methods}

\section{Materials}

The four NRE selected were: US 1043 , US 1045, US 1056, and US 1057. These are complex, hexaploid $V$. ashei-V. constablaei hybrids selected from a breeding project designed to develop cold-hardy rabbiteye-type plants. US 1043 and US 1056 have previously been evaluated for midwinter floral bud cold-hardiness (Ehlenfeldt et al., 2007). Their species composition is: $50 \% \mathrm{~V}$. ashei, $25 \%$ V. constablaei, $18 \%$ V. corymbosum, $5 \%$ $V$. darrowii, and less than $3 \%$ other species (less than $1 \% V$. tenellum Aiton, $2 \% V$. angustifolium Aiton). Among these selections, US 1043 and US 1045 are siblings that have 'Beckyblue' as a $50 \%$ RE parent, and US 1056 and US 1057 are siblings that have 'Premier' as a $50 \%$ RE parent. 'Snowflake'(SNF) (Lyrene, 1993) is a RE-CON hybrid composed of $25 \% \mathrm{~V}$. constablaei and $75 \% \mathrm{~V}$. ashei with both 'Beckyblue' and 'Premier' as grandparents. 'Little Giant' (LIG) is a very cold-hardy RE-CON processing hybrid (small-fruited) that is a 50:50 hybrid of $V$. ashei and $V$. constablaei (U.S. Dept. of Agriculture, 1996). The four RE standards were 'Brightwell' (BRW), 'Climax' (CLX), 'Tifblue' (TIF), and 'Woodard' (WOO). The two HB standards were 'Duke' (DUK) and 'Bluecrop' (BCP), which are tetraploid commercial cultivars chosen for their productivity, better-than-average fertility, and widespread commercial appeal.

\section{Pollinations}

The selections and cultivars were pollinated under greenhouse conditions with either self-pollen or a multicultivar bulk-pollen mixture (appropriate to ploidy level and species) to determine their relative responses to self-pollination and cross-pollination. The hexaploid pollen bulk in both years was a mix of approximately equal amounts of pollen from: CLX, SNF, and WOO as well as 'Beckyblue', 'Montgomery', 'Powderblue', and 'Suwanee'. These pollen sources represented a wide diversity of genetic backgrounds and the mixture was designed to minimize possible incompatibility resulting from genetic relatedness. The tetraploid pollen bulk in both years was a mixture of approximately equal amounts of pollen from: DUK, BCP, and 'Elliott'. These three are common commercial cultivars, are relatively unrelated, and are all considered fertile. The pollen bulks were compounded at the beginning of the experiment and when not in use were stored in glass vials in a refrigerated dessication chamber for the duration of the pollination period ( $\approx 3$ weeks). Pollen was applied with a sharpened pencil tip. All 
pollinations were made in an insect-free greenhouse, and flowers were not emasculated. Pollinations were made on what were judged to be mature stigmas and then repeated $2 \mathrm{~d}$ later. Pollinations were distributed across three to four plants to minimize variability resulting from individual plants. A minimum of 150 pollinations (but not more than 200) were targeted (Table 1); however, this number was not possible for all crosses.

\section{Evaluations}

Data were collected on fruit set (\%), berry weight $(\mathrm{g})$, and seed development (rating mature fruit were sliced equatorially and categorized on the following 1 to 8 rating scale: $1=$ no seed whatsoever; $2=$ no developed seed, only a few very underdeveloped seed; 3 = no well-developed seed, a few underdeveloped seed; 4 = few seed with many underdeveloped; $5=$ few seed of varying levels of development; 6 = few seed but all well developed; 7 = many well-developed seed with a large number of underdeveloped seed; and $8=$ many seed, most, or all, well developed. scale). For seed development evaluations,

\section{Statistical analyses}

The three dependent variables, percent fruit set, berry weight, and seed development, were examined for each genotype, year, and cross type.

Percent fruit set. Percent fruit set was modeled in the generalized linear models framework in R ( $\mathrm{R}$ Development Core Team 2011) using the lme4 package (Bates et al., 2011) as a binomial variable with a logit link and with genotype, year, and cross type (and their interactions) as independent variables. The data, even with all interactions included, had an estimated overdispersion parameter of 2.96. In our experience, this value is typical for data of this nature and may result from inadvertent omission of a predictor variable. More commonly, it arises from unrecognized biological or environmental processes that produce non-independence among berries within a plant (e.g., the plant is stressed that affects all berries on that plant). We included the overdispersion parameter in the model when testing for the significance of effects (this makes the tests more conservative). The means and $95 \%$ confidence intervals were calculated for each genotype $\times$ year $\times$ cross type combination.

Berry weight. Berry weight differences between cross-pollinations and self-pollinations, for each genotype in each year, were evaluated using $\chi^{2}$ tests. The data for both types of pollinations for a given genotype and year were binned into categories with about equal numbers of observations per size category. The numbers depended on how many samples were available and ranged from two to eight. Each category was divided into crosspollinated and self-pollinated to create the $2 \times r$ contingency table for testing where $r$ was the number of size categories.

Seed development. Seed development scores were tested by $\chi^{2} \mathrm{~s}$ in a way similar to that done for berry weight, initially starting with the eight categories, then merging adjacent cells with few observations to ensure that each category had at least 10 observations. The final number of categories ranged from two to seven.

Analyses were initially conducted for each genotype, year, and pollination type class. Subsequently, a similar set of analyses was conducted on merged genotypes grouped by germplasm type (HB, NRE, RE-CON, RE).

\section{Results and Discussion}

for two highbush standards ('Duke', 'Bluecrop'), four northern-adapted rabbiteye selections (US 1043 , US 1045 , US 1056, US 1057), two rabbiteye $\times V$. constablaei derivatives ('Little Giant', 'Snowflake'), and four rabbiteye standards ('Brightwell', 'Climax', 'Tifblue', 'Woodard').

\begin{tabular}{|c|c|c|c|c|c|c|c|c|c|c|c|}
\hline \multirow[b]{2}{*}{ Selection } & \multirow[b]{2}{*}{ Cross } & \multicolumn{2}{|c|}{ No. of pollinations } & \multicolumn{2}{|c|}{ No. of fruit } & \multicolumn{2}{|c|}{ Fruit set $(\%)$} & \multicolumn{2}{|c|}{ Avg berry wt (g) } & \multicolumn{2}{|c|}{ Avg seed scores } \\
\hline & & 2006 & 2007 & 2006 & 2007 & 2006 & 2007 & 2006 & 2007 & 2006 & 2007 \\
\hline$\overline{\text { Bluecrop }}$ & Out & 168 & 190 & 130 & 178 & 77 & 94 & 2.2 & 1.9 & 6.9 & 7.0 \\
\hline Bluecrop & Self & 166 & 207 & 137 & 171 & 83 & 83 & 1.7 & 1.7 & 5.6 & 5.5 \\
\hline Duke & Out & 154 & 165 & 24 & 116 & 16 & 70 & 1.5 & 1.6 & 6.1 & 7.0 \\
\hline Duke & Self & 154 & 199 & 44 & 99 & 29 & 50 & 1.3 & 1.5 & 4.7 & 5.5 \\
\hline US 1043 & Out & 131 & 202 & 71 & 121 & 54 & 60 & 1.2 & 1.1 & 6.8 & 6.7 \\
\hline US 1043 & Self & 160 & 191 & 22 & 39 & 14 & 20 & 0.8 & 0.5 & 5.6 & 4.6 \\
\hline US 1045 & Out & 63 & 108 & 41 & 80 & 65 & 74 & 1.6 & 1.2 & 7.5 & 7.5 \\
\hline US 1045 & Self & 76 & 152 & 10 & 55 & 13 & 36 & 0.6 & 0.7 & 5.3 & 5.9 \\
\hline US 1056 & Out & 167 & 201 & 120 & 129 & 72 & 64 & 1.7 & 1.1 & 7.3 & 6.6 \\
\hline US 1056 & Self & 237 & 190 & 145 & 151 & 61 & 79 & 1.5 & 1.2 & 6.8 & 6.7 \\
\hline US 1057 & Out & 134 & 207 & 97 & 124 & 72 & 60 & 1.1 & 1.0 & 6.3 & 6.9 \\
\hline US 1057 & Self & 185 & 202 & 118 & 114 & 64 & 56 & 1.2 & 0.9 & 5.6 & 5.6 \\
\hline Little Giant & Out & 146 & 193 & 68 & 106 & 47 & 55 & 0.3 & 0.4 & 7.7 & 7.6 \\
\hline Little Giant & Self & 146 & 229 & 34 & 25 & 23 & 11 & 0.2 & 0.3 & 6.2 & 5.2 \\
\hline Snowflake & Out & 162 & 202 & 81 & 140 & 50 & 69 & 0.7 & 1.3 & 4.0 & 6.3 \\
\hline Snowflake & Self & 168 & 216 & 64 & 116 & 38 & 54 & 0.8 & 1.2 & 4.0 & 4.5 \\
\hline Brightwell & Out & 170 & 180 & 74 & 94 & 44 & 52 & 1.3 & 1.4 & 5.9 & 5.6 \\
\hline Brightwell & Self & 148 & 200 & 50 & 63 & 34 & 32 & 1.1 & 1.3 & 3.8 & 4.2 \\
\hline Climax & Out & 186 & 229 & 157 & 167 & 84 & 73 & 1.4 & 1.3 & 6.6 & 6.1 \\
\hline Climax & Self & 182 & 216 & 126 & 99 & 69 & 46 & 1.1 & 0.8 & 2.9 & 2.7 \\
\hline Tifblue & Out & 153 & 239 & 56 & 97 & 37 & 41 & 1.3 & 1.2 & 3.1 & 3.9 \\
\hline Tifblue & Self & 175 & 194 & 27 & 71 & 15 & 37 & 1.2 & 1.1 & 1.0 & 2.1 \\
\hline Woodard & Out & 198 & 206 & 85 & 134 & 43 & 65 & 1.5 & 1.4 & 6.8 & 6.9 \\
\hline Woodard & Self & 193 & 215 & 56 & 88 & 29 & 41 & 1.0 & 1.0 & 4.0 & 4.4 \\
\hline
\end{tabular}

${ }^{\mathrm{z}}$ Seed development scores: 1 = no seed whatsoever; 2 = no developed seed, only a few very underdeveloped seed; 3 = no well-developed seed, a few underdeveloped seed; 4 = few seed with many underdeveloped; $5=$ few seed of varying levels of development; 6 = few seed but all well developed; 7 = many well-developed seed with a large number of underdeveloped seed; 8 = many seed, most, or all, well developed.
Fruit set. The model for percent fruit set had all main effects and two-way interactions significant. Thus, not only did fruit set differ for the main effects (e.g., genotypes, pollination type, and year), but some genotypes also varied in the interaction effects of pollination type $\times$ year. The means and approximate $95 \%$ confidence intervals for each genotype $\times$ year $\times$ pollination type combination are shown in Figure 1 (gray boxes enclose the four estimates for each genotype). Some genotypes (e.g., BCP and US 1056) maintained a high percent fruit set (greater than 65\%) in both years and for both types of crosses (Table 1). In contrast, LIG, US 1043, and US 1045 had a low percent fruit set (less than 25\%) for self-pollinations in both years. Other variability seen for some genotypes is difficult to explain. For example, CLX had low fruit set only in 2007 when self-pollinated, and TIF had very low fruit set only in 2006 for self-pollinations. In no cases was percent fruit set for self-pollinations more than slightly higher than cross-pollinated within years; in most cases, it was lower (21 of 24 comparisons), often substantially lower (exceptions are BC 2006, DUK 2006, US 1056 2007).

The overall cultivar rankings for fruit set (averaged across years and pollination types) were: $\mathrm{BCP}>$ US $1056>$ US $1057>$ CLX > SNF $>$ DUK $>$ WOO $>$ US $1045>$ US $1043>$ LIG $>$ BRW $>$ TIF (Table 2).

Breaking this down, the rankings for fruit set by self-pollination (averaged across years, percent values in bold) were: BCP $\mathbf{8 3}>$ US $1056 \mathbf{7 0}>$ US $1057 \mathbf{6 0}>$ CLX $\mathbf{5 8}>$ SNF $46>$ DUK 39 $>$ WOO $35>$ BRW $33>$ TIF $26>$ US 


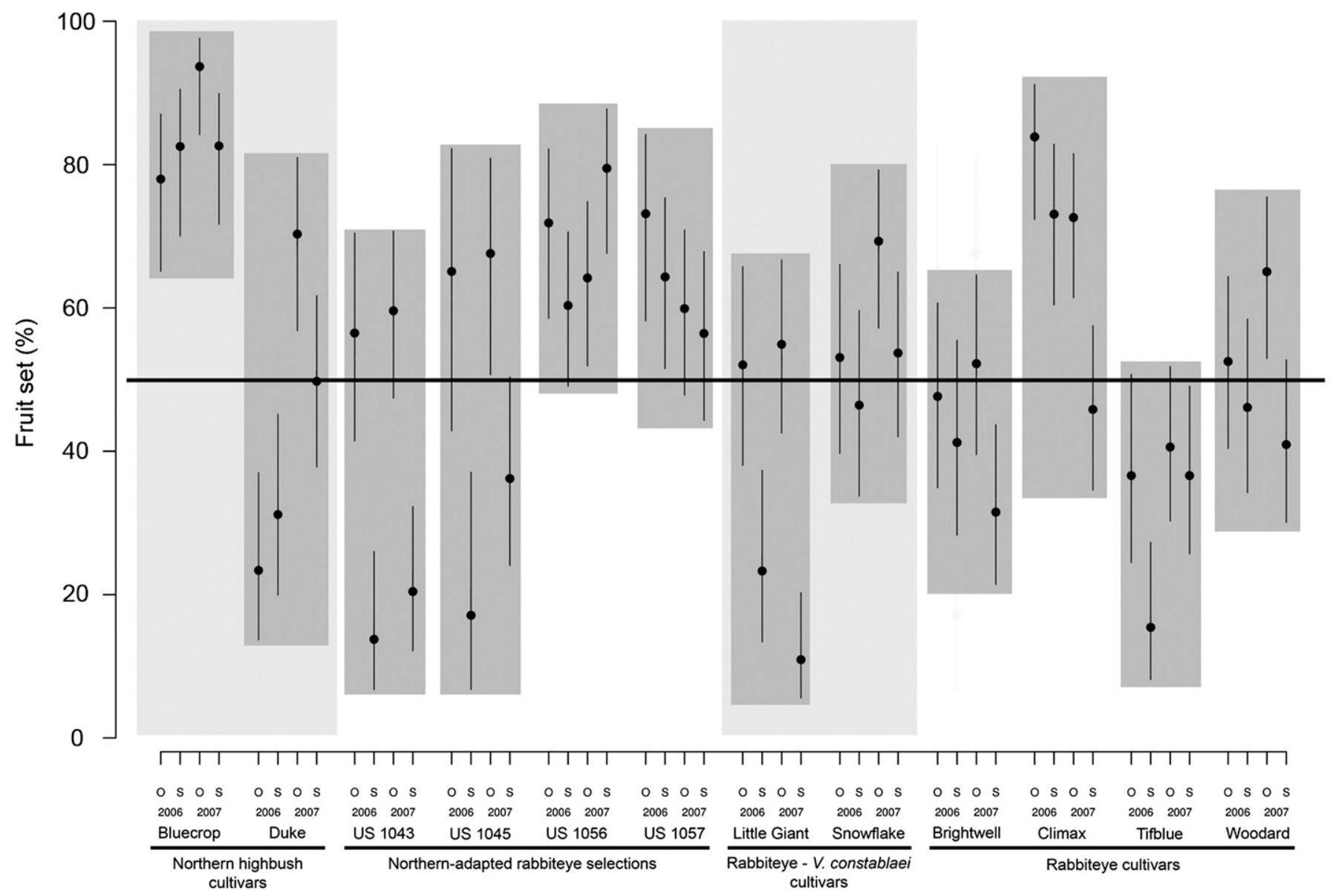

Fig. 1. Fruit set with $95 \%$ confidence intervals for two highbush standards ('Duke', 'Bluecrop'), four northern-adapted rabbiteye selections (US 1043 , US 1045 , US 1056, US 1057), two rabbiteye $\times V$. constablaei derivatives ('Little Giant', 'Snowflake'), and four rabbiteye standards ('Brightwell', 'Climax', 'Tifblue', 'Woodard').

104525 > US $104317>$ LIG 17 (Table 2). Based on these values, US 1056 and US 1057 appeared better than most RE cultivars with regard to self-pollinated fruit set.

Similarly, if we examine rankings for fruit set when cross-pollinated (averaged across years, percent values in bold), we find: $\mathrm{BCP}$ $86>$ CLX $79>$ US $104570>$ US $105668>$ US $105766>$ SNF $60>$ US $104357>$ WOO $54>$ LIG $51>$ BRW $48>$ DUKE $43>$ TIF 39 (Table 2). NRE were better than most RE cultivars when cross-pollinated, and DUK did surprisingly poorly with respect to fruit set with cross-pollination in 2006, which lowered its average.

Berry weight. Although berry weight is largely a function of genotype, our interest in examining berry weight was to see if it is influenced by type of pollination. The $P$ values for the $\chi^{2}$ tests (for self-pollinated vs. cross-pollinated) ranged from 0.000 to 0.575 with 15 of 24 of the comparisons below 0.05 (i.e., significantly different; by chance, one would expect 1.2 of 24 significant at $\alpha=$ 0.05 ) (results not shown). Genotypes with non-significant comparisons between pollination types were: BRW $(2006,2007)$, DUK (2006, 2007), SNF (2006), TIF (2006, 2007), US 1056 (2007), and US 1057 (2006) (Table 1).

The distribution of berry weights for each genotype-year combination is shown in
Figure 2 as box plots (boxes above and below the median are quartiles), where asterisks denote significant differences between the cross-pollinated and self-pollinated members of a pair. Note that this evaluation tested for differences in distribution location and shape, not mean or median difference. However, in all cases in which significant differences were observed, the median berry weight of self-pollinations was lower than that for cross-pollinations. Most genotypes had considerable variability in berry weight, the exception being LIG, which had a relatively low berry weight for all four year $\times$ pollination type groups. (LIG, as a processing variety, is a naturally smaller-fruited genotype.) Even for this genotype, median berry weight was lower for self-pollinated fruit (comparisons for both 2006 and 2007 were significant). BRW, DUK, and TIF were the only genotypes in which there was not a significant difference in at least one of the years.

Separating berry weight by cross type, the overall rankings (in grams) for self-pollination, averaged across years, were: BCP $1.7 \mathrm{~g}>$ DUK $1.4 \mathrm{~g}>$ US $10561.3 \mathrm{~g}>(\mathrm{BRW}=\mathrm{TIF}$ $\mathbf{1 . 2} \mathrm{g})>(\mathrm{US} 1057=\mathrm{SNF}=$ WOO $\mathbf{1 . 0} \mathrm{g})>$ CLX $0.9 \mathrm{~g}>$ (US $1045=$ US $10430.6 \mathrm{~g}$ ) > LIG $0.3 \mathrm{~g}$ (Table 2). A main finding is that some NRE genotypes, particularly US 1056, perform almost as well as highbush standards such as DUK and BCP with respect to berry size on self-pollination.

Similarly, the rankings for berry weight for cross-pollination, averaged across years, were: BCP 2.0 $\mathrm{g}>$ DUK 1.6 $\mathrm{g}>$ (US 1045 = US $1056=$ WOO $1.4 \mathrm{~g})>(\mathrm{BRW}=\mathrm{CLX} 1.3 \mathrm{~g})>\operatorname{TIF} 1.2 \mathrm{~g}>$ US $1043 \mathbf{1 . 1} \mathrm{g}>($ US $1057=$ SNF $\mathbf{1 . 0} \mathrm{g})>$ LIG $0.4 \mathrm{~g}$ (Table 2). Again, NREs were variable, but some NREs such as US 1056 and US 1045 , on cross-pollination, were nearly as good as HB.

Seed development. Seed development scores are an ordinal categorical variable so interpretation of means or medians can be problematic. Nevertheless, we provide mean seed development scores in Table 1.

The $P$ values from $\chi^{2}$ tests for seed development (of self-pollinated vs. crosspollinated) ranged from 0.000 to 0.789 with 21 of 24 having $P$ values $<0.05$. The three non-significant comparisons were DUK in 2006 and US 1056 in 2006 and 2007. In general, cross-pollinated fruit tended to have higher counts for categories 7 and 8 (i.e., many seeds) than did self-pollinated fruits (median scores for cross-pollinated were all greater than or equal to corresponding selfpollinated scores). We did not see other consistent trends for this comparison. Ratings in 2006 tended to concentrate seed 
Table 2. Fruit set, berry weight, and seed development scores averaged across years for germplasm groups and for individual clones: two highbush standards ('Duke', 'Bluecrop'), four northern-adapted rabbiteye selections (US 1043, US 1045, US 1056, US 1057), two rabbiteye $\times$ V. constablaei derivatives ('Little Giant', 'Snowflake'), and four rabbiteye standards ('Brightwell', 'Climax', 'Tifblue', 'Woodard').

\begin{tabular}{|c|c|c|c|c|c|c|c|c|c|}
\hline Germplasm type & $\begin{array}{c}\text { Pollination } \\
\text { type }\end{array}$ & $\begin{array}{c}\text { Fruit set } \\
(\%)\end{array}$ & Berry wt (g) & $\begin{array}{l}\text { Seed development } \\
\text { score }^{\mathrm{z}}\end{array}$ & Genotype & $\begin{array}{c}\text { Pollination } \\
\text { type }\end{array}$ & $\begin{array}{c}\text { Fruit set } \\
(\%)\end{array}$ & Berry wt (g) & $\begin{array}{c}\text { Seed developmen } \\
\text { score }^{\mathrm{z}}\end{array}$ \\
\hline & Self & 60.9 & 1.6 & 5.3 & Bluecrop & Self & 82.6 & 1.7 & 5.6 \\
\hline & & & & & Duke & Out & 42.9 & 1.6 & 6.6 \\
\hline \multirow{5}{*}{$\begin{array}{l}\text { Northern-adapted } \\
\text { rabbiteye }\end{array}$} & Out & 65.2 & 1.2 & 7.0 & US 1043 & Out & 57.0 & 1.1 & 6.8 \\
\hline & Self & 43.1 & 0.9 & 5.8 & US 1043 & Self & 17.1 & 0.6 & 5.1 \\
\hline & & & & & US 1056 & Self & 70.3 & 1.3 & 6.8 \\
\hline & & & & & US 1057 & Out & 66.1 & 1.0 & 6.6 \\
\hline & & & & & US 1057 & Self & 60.1 & 1.0 & 5.6 \\
\hline \multirow{2}{*}{$\begin{array}{l}\text { Rabbiteye- } \\
\quad \text { V. constablaei }\end{array}$} & Out & 55.1 & 0.7 & 6.4 & Little Giant & Out & 50.7 & 0.4 & 7.7 \\
\hline & Self & 31.5 & 0.7 & 5.0 & Little Giant & Self & 17.1 & 0.3 & 5.7 \\
\hline & & & & & Climax & Out & 78.7 & 1.3 & 6.4 \\
\hline & & & & & Climax & Self & 57.5 & 0.9 & 2.8 \\
\hline & & & & & Tifblue & Out & 38.6 & 1.2 & 3.5 \\
\hline & & & & & Tifblue & Self & 26.0 & 1.2 & 1.6 \\
\hline & & & & & Woodard & Out & 54.0 & 1.4 & 6.9 \\
\hline & & & & & Woodard & Self & 35.0 & 1.0 & 4.2 \\
\hline
\end{tabular}

${ }^{\mathrm{z}}$ Seed development scores: 1 = no seed whatsoever; 2 = no developed seed, only a few very underdeveloped seed; $3=$ no well-developed seed, a few underdeveloped seed; 4 = few seed with many underdeveloped; $5=$ few seed of varying levels of development; $6=$ few seed but all well developed; $7=$ many welldeveloped seed with a large number of underdeveloped seed; 8 = many seed, most, or all, well developed.

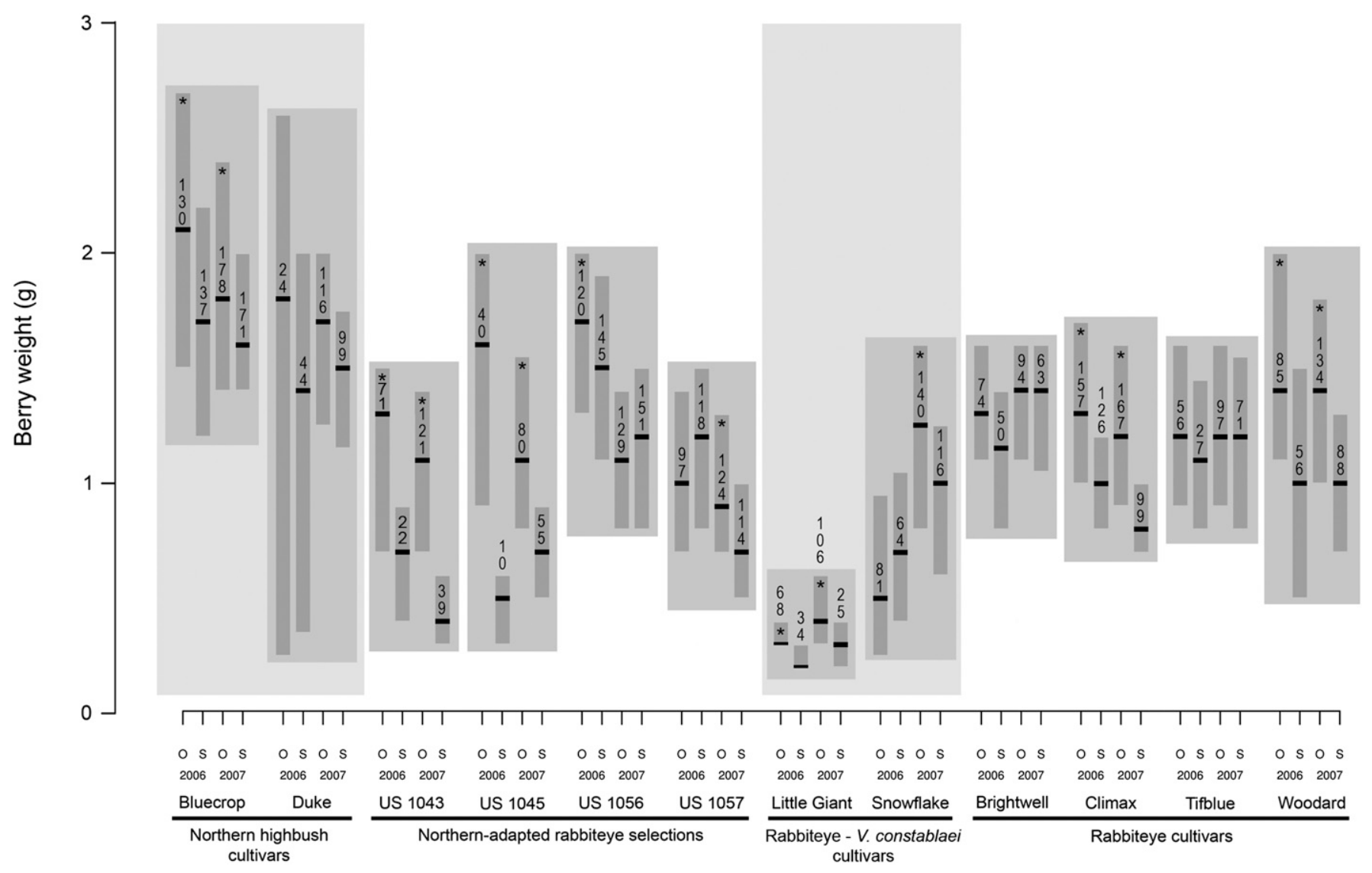

Fig. 2. Fruit weight distributions for two highbush standards ('Duke', 'Bluecrop'), four northern-adapted rabbiteye selections (US 1043, US 1045, US 1056, US 1057), two rabbiteye $\times V$. constablaei derivatives ('Little Giant', 'Snowflake'), and four rabbiteye standards ('Brightwell', 'Climax', 'Tifblue', 'Woodard'). Bars represent medians and quartiles above and below the median. Numbers indicate entire sample size (all quartiles). 
development scores in just a few categories, whereas ratings in 2007 had scores more evenly distributed across the categories, perhaps reflecting a small change in how seeds were rated. The distributions of scores were variable across genotypes.

Overall rankings for seed development scores averaged across years and pollination type were: US 1056 6.9 > LIG 6.7 > US 1045 6.6 > BCP 6.3 > US 1057 6.1 > US 1043 5.9> DUK 5.9 $>$ WOO 5.5 $>$ BRW 4.9 $>$ SNF $4.7>$ CLX 4.6 > TIF 2.5 (Table 2).

Overall rankings for seed development scores averaged across years for selfpollination were: US $1056 \mathbf{6 . 7}>$ LIG $5.7>$ $(\mathrm{BCP}=\mathrm{US} 1045=\mathrm{US} 1057$ 5.6 $)>(\mathrm{DUK}=$ US 1043 5.1 $)>(\mathrm{SNF}=\mathrm{WOO}$ 4.2 $)>\mathrm{BRW} 4.0>$ CLX 2.8 > TIF 1.5 (Table 2). In this ranking, three of the four NRE selections were midrange; however, US 1056 was better than all other cultivars of any type.

Overall rankings for seed development scores averaged across years for crosspollination were: LIG 7.6 > US $10457.5>$ US $10567.0>$ BCP $6.9>$ WOO $6.8>$ (DUK $=$ US $1043=$ US 1057 6.6) $>$ CLX 6.3 $>$ BRW 5.7 > SNF $5.1>$ TIF 3.5 (Table 2). LIG displayed a surprisingly high level of seed development. US 1045 and US 1056 were both very good; the other NREs can be considered midrange.
Evaluation of genotypes grouped by germplasm class. Analyses of merged germplasm classes produced results essentially similar to those for individual genotypes. Percent fruit set again required a model with three-way interaction terms. The NRE category was involved in most of the significant terms, suggesting that NRE genotypes differed from those in other groups in the effects of cross-pollination vs. self-pollination, although not always in a clear way. For example, for fruit set in 2006, the difference between outcrossing and selfing is almost $17 \%$ larger for NRE than for other groups, but in 2007, the difference was $9 \%$ smaller. The results for berry weight showed significant differences for the cross-pollinated vs. selfpollinated distributions for all categories except NRE in 2006, suggesting that overall NRE are equivalent for berry weight whether self-pollinated or cross-pollinated. For seed development scores, all comparisons were significant. The median seed development score was higher for cross-pollinations vs. self-pollinations for all groups in both years except for NRE. For NRE, the median scores were the same in both years (ratings of 7 or 8); the distributions differed slightly in how scores were distributed on either side of the median. Given the large sample sizes created in this data set when merging data from several genotypes into single genotype categories, one expects $P$ values for this type of test to be significant for even small (and likely biologically unimportant) differences.

Finally, a graph of seed development scores vs. fruit set does much to visualize how these clones behave in a relative manner. Figure 3 shows mean seed development scores vs. mean proportion fruit set for selfpollination and cross-pollination in 2006 and 2007. The lines connect the values for 2006 and 2007 with clone labels at the 2006 end of the lines. Self-pollinations are labeled in italics with dotted lines; cross-pollinations are non-italic with solid lines. What is observed broadly is that self-pollinations tend to group toward the lower values on the fruit set axis (x-axis); cross-pollinations tend toward the higher values on the axis. With few exceptions, years mostly affected proportion fruit set (lines connecting years are mostly horizontal) and proportion fruit set was higher in 2007.

Looking primarily at values for "fruit set," we can see that self-pollinations of three genotypes (BCP, US 1056, US 1057) in both years, and one genotype (CLX) in 2006, behaved comparably to cross-pollinations. DUK in 2006 performed poorly for crosspollinated fruit set. Based on field observations of DUK, we consider 2007 to be more typical

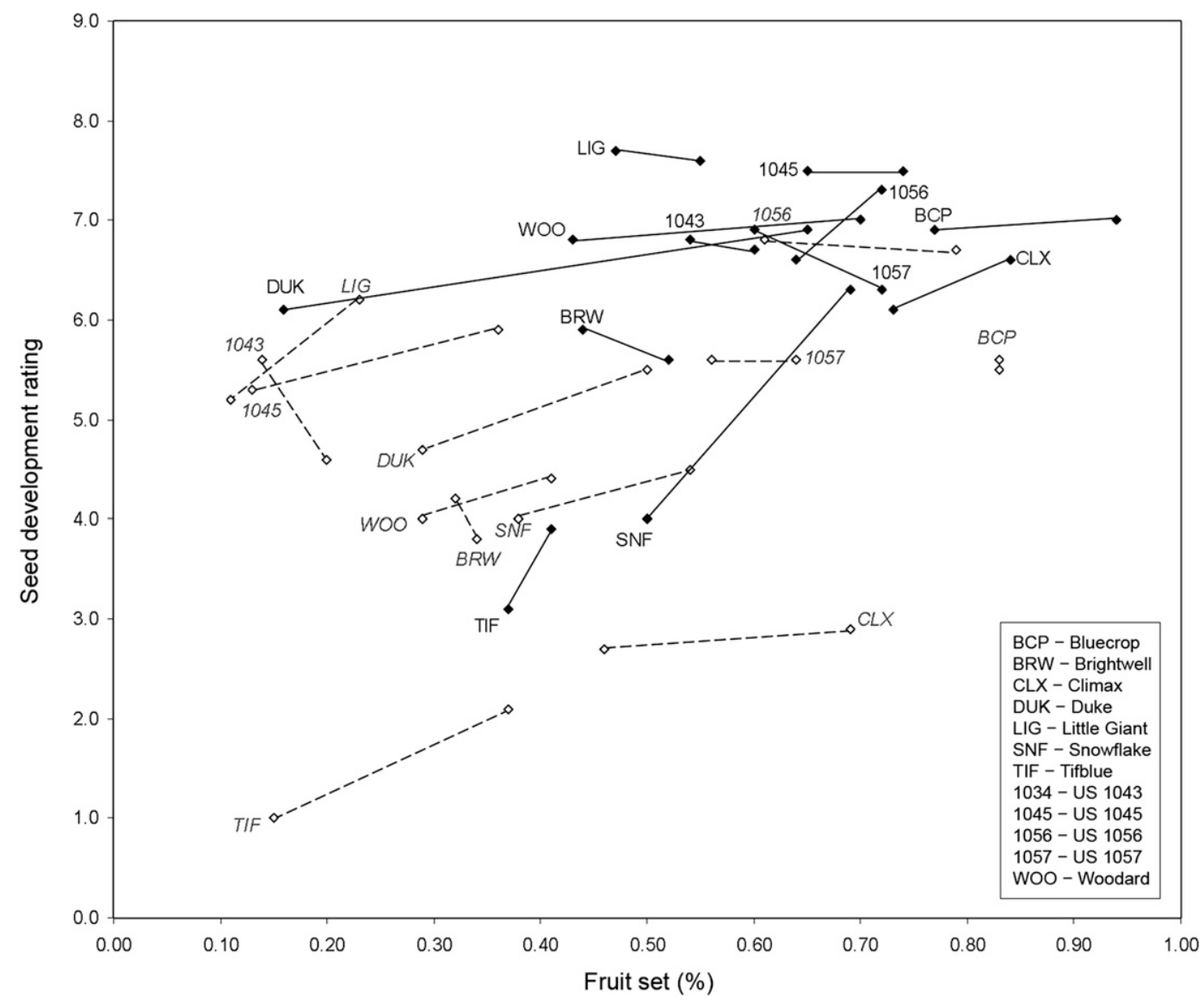

Fig. 3. Seed development vs. fruit set for self-pollinations and cross-pollinations in 2006 and 2007 for two highbush standards ('Duke', 'Bluecrop'), four northernadapted rabbiteye selections (US 1043, US 1045, US 1056, US 1057), two rabbiteye $\times$ V. constablaei derivatives ('Little Giant', 'Snowflake'), and four rabbiteye standards ('Brightwell', 'Climax', 'Tifblue', 'Woodard'). The lines connect the values for 2006 and 2007 with labels at the 2006 end of the lines. Self-pollinations are represented by italic labels with dotted lines; cross-pollinations by non-italic labels with solid lines. 
behavior, and we consider 2006 an unexplained anomaly. Similarly, cross-pollinations of TIF performed poorly with regard to fruit set in both years with results similar to the self-pollinations.

In subsequent seed development (y-axis), TIF and CLX self-pollinations performed extremely poorly. RE self-pollinations would not be expected to do well, but these performed worse than the other RE cultivars (e.g., BRW, WOO). TIF cross-pollinations performed worse than most selections. SNF (a RE-CON type) performed poorly in 2006 . The NREs, our major concern in this experiment, performed reasonably well with respect to development with almost none scoring less than 5 and several cross-pollinations (US 1043, US 1045, US 1056, and US 1057) scoring above 7 . The self-pollinations of US 1056 are notable for having the best development of any self-pollinations tested (greater than 7). LIG (another RE-CON type) was notable for best seed development from outcrossing.

\section{Conclusion}

The NREs performed variably with respect to fruit set when self-pollinated; some did poorly and some did very well. The NREs were less variable for seed development, appearing to be better than most RE when self-pollinated and comparable to HB when cross-pollinated.

For self-fertility, the major conclusion is that NREs seem to be better overall than RE but have mixed results compared with HB. Some clones, like US 1056, performed comparably to the limited selection of HB standards. These results suggest NRE have potential for high fertility when derived from appropriate parents and when self-fertility and self-fruitfulness are placed as evaluation priorities. Naturally self-fertile selections are more likely to succeed in larger solid-planted field blocks.

As a final proviso, this study was done under greenhouse conditions, and poor fertility results may be a result of interactions with the greenhouse environment. However, we believe that clones that have higher fruit set and better seed development under greenhouse conditions are also likely to also do well under field conditions. Our field observations of US 1056 (unpublished results) confirm the expectations derived from this greenhouse data.

\section{Literature Cited}

Bates, D., M. Maechler, and B. Bolker. 2011. lme4: Linear mixed-effects models using S4 classes. R package version 0.999375-42. <http://CRAN.Rproject.org/package $=1 \mathrm{me} 4>$.

Brightwell, W.T., O.J. Woodard, G.M. Darrow, and D.H. Scott. 1955. Observations on breeding blueberries for the Southeast. Proc. Amer. Soc. Hort. Sci. 65:274-278.

Coville, F.V. 1921. Directions for blueberry culture. U.S. Dept. of Agr. Bul. 974.

Ehlenfeldt, M.K. 2001. Self- and cross-fertility in recently released highbush blueberry cultivars. HortScience 36:133-135.

Ehlenfeldt, M.K., L.J. Rowland, E.L. Ogden, and B. Vinyard. 2012. Cold-hardiness, acclimation, and deacclimation among diverse blueberry genotypes. J. Amer. Soc. Hort. Sci. 137:31-37.

Ehlenfeldt, M.K., L.J. Rowland, E.L. Ogden, and B.T. Vinyard. 2007. Floral bud cold hardiness of Vaccinium ashei, V. constablaei, and hybrid derivatives and their potential for producing northern-adapted rabbiteye cultivars. HortScience 42:1131-1134.

El-Agamy, S.Z.A., W.B. Sherman, and P.M. Lyrene. 1981. Fruit set and seed number from self- and cross-pollinated highbush $(4 x)$ and rabbiteye (6x) blueberries. J. Amer. Soc. Hort. Sci. 106:443-445.

Krewer, G. and D.S. NeSmith. 2006. Blueberry cultivars for Georgia. Oct. 2006, <http://www. smallfruits.org/Blueberries/production/06bbcvproc_ Nov0206.pdf $>$.

Lyrene, P.M. 1993. Rabbiteye blueberry cultivar 'Snowflake'. U.S. Plant Patent 8,082, filed 10 Jan. 1991 and issued 5 Jan. 1993.

Meader, E.M. and G.M. Darrow. 1944. Pollination of the rabbiteye blueberry and related species. Proc. Amer. Soc. Hort. Sci. 45:267274.

Meader, E.M. and G.M. Darrow. 1947. Highbush blueberry pollination experiments. Proc. Amer. Soc. Hort. Sci. 49:196-204.

Merrill, T.A. 1936. Pollination of the highbush blueberry. Mich. Agr. Expt. Sta. Tech. Bul. 181.

R Development Core Team. 2011. R: A language and environment for statistical computing. $\mathrm{R}$ Foundation for Statistical Computing, Vienna, Austria. <http://www.R-project.org/>.

Strik, B.C. and D. Yarborough. 2005. Blueberry production trends in North America, 1992 to 2003, and predictions for growth. HortTechnology 15:391-398.

U.S. Dept. of Agriculture. 1996. Notice of release of 'Little Giant' hybrid blueberry. USDA, Beltsville, MD. 